\title{
Um projeto para o Brasil: arquitetura e política na trajetória de Lina Bo Bardi no Brasil, 1946-1977
}

\author{
André Augusto de Almeida Alves \\ Arquiteto e urbanista, doutor pela Faculdade de Arquitetura e \\ Urbanismo FAU-USP, professor adjunto da Universidade Estadual \\ de Maringá, Avenida Colombo, 5790, Jardim Universitario, \\ Maringá, PR, CEP 87020-900, (44) 3011-4040, almeida.alves@ \\ gmail.com
}

\section{Resumo}

Combinando um aguçado olhar estrangeiro e a paixão pela civilização e homem brasileiro, uma atuação plural e uma rica experiência em que se defronta com as dramáticas realidades do século XX no Brasil e além, Lina Bo Bardi participa intensivamente do debate sobre a modernização do país, concebendo verdadeiro projeto de nação moderna. A trajetória da arquiteta adquire, assim, inevitável dimensão política, que se busca aqui compreender.

Palavras-chave: modernização, arquitetura moderna, Brasil.

uitas são as faces da produção de Lina Bo Bardi, que ratifica a magnitude da sua contribuição à cultura e à arquitetura de seu tempo, Ihe granjeia duradouro reconhecimento e resulta na atualidade sua obra.

Ao aprofundar a compreensão deste legado, a historiografia paulatinamente contribui para ressituar o papel da arquiteta não só na construção da cultura, mas da própria modernidade brasileira.

Tão famosa quanto controversa é a referência de Bruand à casa de vidro enquanto "sutil mistura entre um gosto artesanal muito seguro e o emprego de uma técnica industrial avançada" (Bruand, 2002, p. 267), no capítulo dedicado à "continuidade racionalista". O mesmo estranhamento provoca, atualmente, a definição do MASP como elemento de ligação entre a experiência carioca e a paulista, numa lógica em que "a arquiteta italiana afastou-se da tendência que até então fora uma das marcas registradas da arquitetura brasileira dominada pela escola carioca", aproximando-se "das pesquisas opostas, feitas na mesma época pelo movimento original que florescia em São Paulo, sob a própria influência de Vilanova Artigas" (Bruand, 2002, p.268). Importa aqui o fato de que se faz presente neste construto, ainda que não de forma explícita, a questão do projeto modernizador brasileiro - neste caso, segundo chave localizada na recorrente relação entre "unidade" e "diversidade", na "maturidade" da "nova arquitetura brasileira".

Nesse sentido, se de um lado a afirmação, num dos trabalhos acadêmicos pioneiros sobre a arquiteta, de que "a atividade crítica de Lina Bo Bardi esteve sempre na perspectiva do que chamamos de Projeto de Brasil Moderno", coroa as realizações de Lina Bo Bardi em âmbitos como os da arquitetura, do design, da crítica e museologia entre 1947 e 1957, por outro lado ainda remete à arquitetura da construção da identidade nacional e seus antecedentes na industrialização brasileira dos anos 1930 e numa base cultural antevista na Semana de 1922 (Azevedo, 1995, p. 48), em termos de "composição", "vinculação" e "enquadramento" (1995, p. 44-5).

Esta questão não passa despercebida por Oliveira (2006, p. 17), que ao tratar das formulações de Lucio Costa sobre tradição e modernidade, pondera 
que "não é equivocado afirmar que a obra de Lina encontra-se, de certa forma, na contracorrente da arquitetura moderna produzida no Brasil". Na verdade, este alerta sucede outro, direcionado contra "uma certa leitura bastante confusa e obscurantista em suas implicações políticas... que pretende inserila em uma linha de pensamento utópico-imobilista originária das vanguardas modernas europeias" - de novo, o "racionalismo" - em que "a idéia de progresso sobrepujou a dimensão histórica e acabou legitimando concepções apolíticas destruidoras" (Oliveira, 2006, p. 16). Sem chancelar a ligação de Lina Bo Bardi ao projeto moderno brasileiro conforme consubstanciado por Lúcio Costa, Oliveira aponta o conteúdo e sentido político da atuação da arquiteta.

Desponta aqui a questão da relação entre Lina Bo Bardi e o projeto modernizador brasileiro, que se busca no presente artigo aprofundar.

No que concerne ao seu enfrentamento, é igualmente perceptível a recorrência de tópicos como a consistência e longevidade dos valores e referências da arquiteta e suas raízes na formação e atuação na Itália. No caso de Oliveira (2006) se desdobram "numa unidade tal capaz de anular toda a sequência temporal biográfica", na diluição da noção cronológica de tempo - e de espaço - e numa atitude em que edifícios, junto com escritos e outros "dados, materiais, restos, detritos e detalhes inadvertidos" são vistos como "estrelas que brilham com luz própria". Diversamente, Rubino (2002), focaliza os conteúdos agregados pelos agentes sociais a uma modernidade entendida como prática, a partir de um "onde-quando-quem" que visa contribuir para uma geografia histórica do modernismo, por meio da trajetória de Lina Bo Bardi. As noções de trajetória (Bourdieu) -, de construção da auto-identidade e da imagem pública pelo artista moderno e burguês (Giddens), e de constelação (Benjamin), conforme vistas nestas autoras, contribuem para a elucidação da produção da arquiteta.

Estas breves considerações revelam-se pertinentes por convergirem com o escopo do presente artigo. Nele, pretende-se desenvolver a hipótese de que a dimensão política perpassa a obra da arquiteta, informando não apenas nas entrelinhas suas múltiplas faces e referências, mas explicitandose de modo sistemático na interação com outros agentes com quem debate e luta, em diferentes temas, personagens, lugares, tempos e conjunturas, portadora de seu projeto de Brasil moderno. Para tanto, parte-se das fontes bibliográficas existentes sobre a arquiteta, através das quais se aproxima a abordagem aqui estabelecida com o estado da arte. Privilegia-se, assim, aproximações em que afloram a percepção, conteúdo e sentido político do pensamento da arquiteta.

\section{Da Itália ao Brasil}

A abrangência e acuidade do olhar de Lina Bo Bardi, capaz de abarcar questões as mais amplas da história, da arquitetura e da sociedade de sua época - das transformações produtivas ocorridas a partir do século XIX até a revisão da arquitetura moderna no segundo pós-guerra -, marca uma experiência de modernidade que, mantendo-se sempre íntegra, constitui-se e encontra diferentes expressões na Itália, em seus primeiros anos em São Paulo, na Bahia ou após a sua volta a São Paulo, após o golpe militar. Lima (2013, p. 3), assim se refere ao público que visita a primeira exposição da obra de Lina, na FAUUSP, em 1989:

\begin{abstract}
...Not could they see that the work she had developed as an architect, designer, illustrator, writer, editor, and curator had emerged from her transit between two countries and, specially, among different cities. Rome and Milan, in Italy, and São Paulo, Salvador and, in a lesser extent, Rio de Janeiro, in Brazil. In both countries, she had witnessed significant moments of cultural and economic modernization marked by strong political tensions and unequal social realities.
\end{abstract}

Gradua-se em arquitetura em Roma em 1939 e, logo depois, parte para Milão onde desenvolve projetos e trabalhos em diversas revistas, com Gio Ponti e Carlo Pagani; co-dirige Domus com este arquiteto de 1943 a 1945, período em que, segundo Anelli (2010, p. 95) a revista "se torna um importante instrumento de preparação dos temas que dominaram o debate arquitetônico do segundo pós-guerra". Participa da fundação do Movimento di Studi per l'Architettura, num período em que o enfrentamento da destruição causada pela guerra e a tarefa de reconstrução desperta uma intensa atuação política ${ }^{1}$ em que, como apontam Miotto e Nicolini (1998, p. 12), o homem ocupa posição central: "sulle macerie di uma società pomposa, ipocrita, il senso della ricostruzione, e di 
2 Azevedo (1995: 5) cita Arendt, que enfatiza a necessidade da prática discursiva que confere relevância ao ato criativo.

3 Azevedo (1995: 8) assinala uma única oportunidade em que Lina faz referência direta a Gramsci em Tempos de Grossura: o design no impasse (1994), e aponta que, segundo Marcelo Ferraz, ela sempre referia-se a ele em conversas. Carranza (2014, p. 121), parte da consideração, por Lina, do nacional enquanto nacional-popular, de extração gramsciana, discorrendo sobre sua origem na militância no $\mathrm{PCl}$, o contato de Lina com Carlos Nelson Coutinho, (2014, p. 123-5) definindo tal conceito como "uma das chaves para entender melhor a obra de Lina Bo e seu perfil contestador" (2014, p. 125).

Figura 1: Lina Bo Bardi no Navio Almirante Jaceguay, 1946. Fonte: Instituto Lina Bo e P. M. Bardi, 1993. conseguenza l'architettura, è spinto da um impulso civile e morale".

Não se tratando, conforme aponta Azevedo (1995: 5), "de entender o mundo, mas de transformá-lo", tal atuação política passa pela reconstrução dos fundamentos éticos da ação projetual, entendida ao mesmo tempo como prática profissional e cultural², incorporando a cultura "como principal lastro para a medida do político" e apresentando, assim, "notável afinidade com os termos gramscianos de cultura popular e intelectual orgânico" ${ }^{3}$. Tal postura está na base da série de artigos escritos para o Milano Sera, que a faz visitar logo após o Armistício, com Carlo Pagani e o fotógrafo Federico Patellani, os locais da Itália mais atingidos pelos bombardeios; bem como da criação, com Carlo Pagani e Bruno Zevi, da revista quinzenal de efêmera duração intitulada $A$ - cultura della vita, que dirige-se à difusão às classes menos favorecidas um modo de habitar "racional", despindo o comportamento e os hábitos de significados "áulico-retóricos", vendo-os como aspecto prático da cultura e despertando desde já o interesse de Lina pela abordagem antropológica: "archeologia del cotidiano e modernità divengono così polarità non contrapostte, ma fecondanti di uma nuova idea di architettura"'4 (Miotto e Nicolini, 1998, p. 13).

Estas são as experiências, interesses e referências intelectuais que Lina Bo Bardi traz consigo ao Brasil em 1946. Cabe notar, portanto, que existe uma bagagem que tende a ser sobreposta pelos relatos otimistas que faz de sua chegada, com recepção na sede do IAB/RJ ${ }^{5}$ (Instituto Lina Bo e P. M. Bardi, 1993, p.12), pelas imagens em diferentes embarcações que a enfatizam (Figura1), sua descrição de Brazil Builds (1943) como "um farol de luz a resplandecer em um campo de morte" (Bardi, 1990, p. 103), ou pelo seu "Currículo literário" (1993), em que contrapõe o deslumbre e a felicidade de sua chegada a reminiscências da guerra e suas ruínas:

Chegada ao Rio de Janeiro de navio em outubro. Deslumbre, para quem chegava pelo mar, o Ministério da Educação e Saúde avançava como

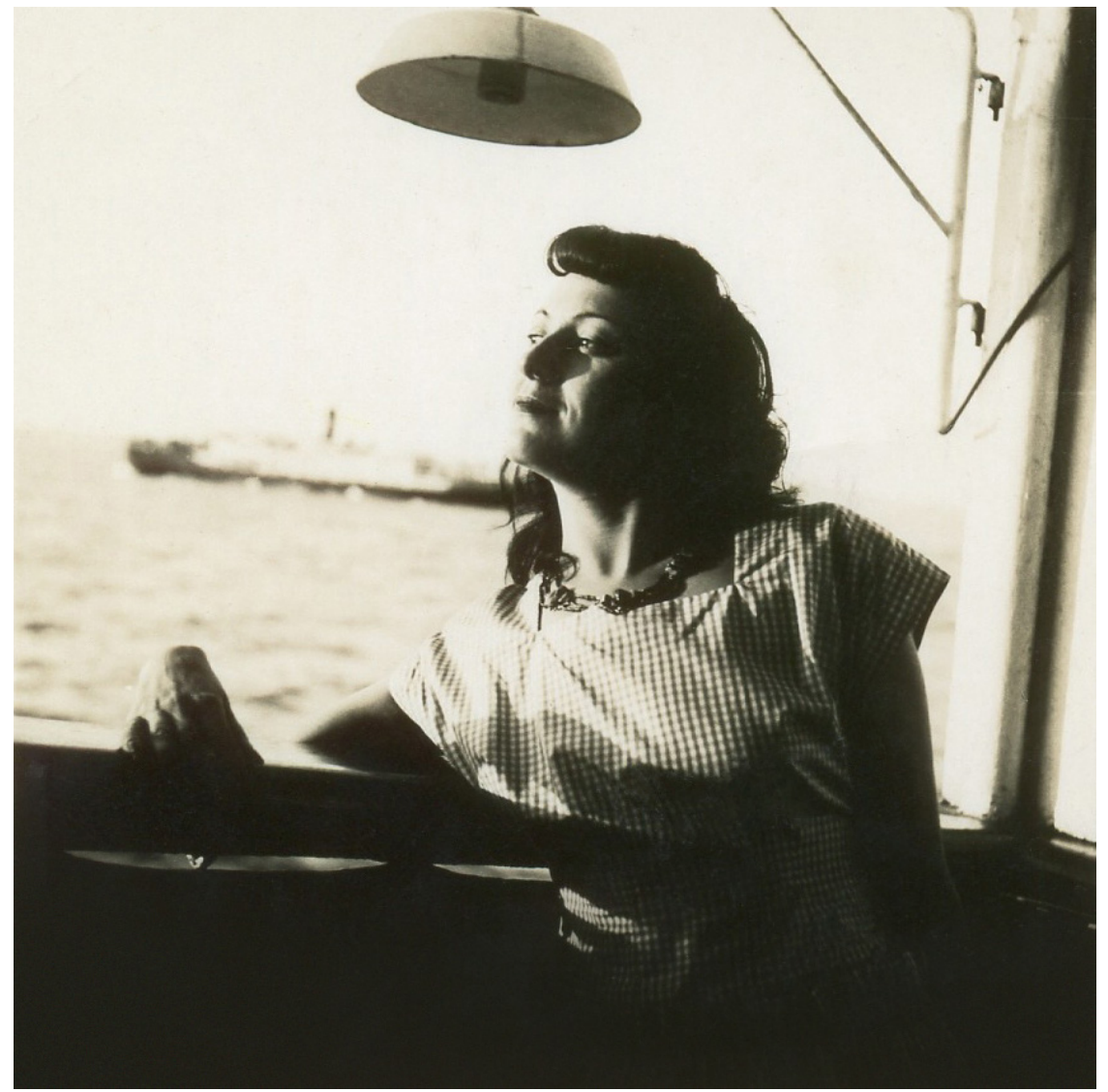


4 Tais experiências jornalísticas têm paralelos com a pesquisa de antropologia urbana realizada no East End de Londres por Peter e Alison Smithson no início da década de 1950, em que reagem ao "people detailling" ligam-se diretamente às raízes sócio-antropológicas da cultura popular e à art brut de Jean Dubuffet, além da produção do fotógrafo Nigel Henderson e do escultor Eduardo Paolozzi.

5 Evento de que participa personalidades como Oscar Niemeyer, Lúcio Costa, irmãos Roberto, Athos Bulcão e Burle-Marx (Instituto Lina Bo e P. M. Bardi, 1993, p. 12).

6 Criado com Giancarlo Palanti em 1948

7 Era uma grande reserva de Mata Brasileira cheia de bichos selvagens: jaguatiricas, tatus. Veadinhos, preás, sariguis, preguiças... Era também uma reserva de pássaros, aparecendo durante o dia almas de gato, peiticas sabiás-laranjeira e sabiás-pretos, anus, bem-te-vis, anhambus, juritis, seriemas, e à noite: curiambos, caborés, corujas e outras aves noturnas... (Instituto Lina Bo e P. M. Bardi, 1993, p. 78).

8 No que Rubino (2009, p 29) define como um tripé que dava vida ao MASP: seu acervo, a revista Habitat e o IAC. Anelli (sd, p. 30) ressalta que a amplitude da atuação da arquiteta deve incorporar uma análise conjunta "das estratégias adotadas por ela junto a Pietro Maria Bardi em suas ações de transformação da cultura brasileira" a partir de São Paulo.

9 Lecionam no IAC aquitetos e artistas como Rino Levi, Oswaldo Bratke, Eduardo Kneese de Melo, Roberto Burle Marx, Jacob Ruchti, Lasar Segall, Giancarlo Palanti, Elisabeth Nobling e Alcides da Rocha Miranda (Anelli, sd., p. 31). um grande navio branco e azul contra o céu. A primeira mensagem de paz após o dilúvio da Segunda Guerra Mundial. Me senti num país inimaginável, onde tudo era possível. Me senti feliz, e no Rio de Janeiro não tinha ruínas. (Instituto Lina Bo e P. M. Bardi, 1993, p. 12)

Interessa aqui apontar o que esta bagagem traz de continuidade na experiência da arquiteta, especialmente em relação a seu repertório crítico. Logo após a sua chegada no Rio de Janeiro, publica em português o artigo "Na Europa a casa do homem ruiu" (1947). em que vê a casa como baluarte de valores da civilização ocidental, ambos reduzidos a pó pela guerra, num quadro em que "as casas(...) eram 'o homem'" em sua fragilidade, vícios e no vazio deixado pela sua destruição, a ser preenchido por valores humanistas. Dois anos depois, escreve para o Diário de São Paulo o artigo "Uma cadeira de grumixaba e taboa é mais moral que um divã de babados" (1949), contemporaneamente à concepção, no Studio d'Arte Palma ${ }^{6}$, de designs baseados no trato com as madeiras e fibras vegetais nativas, que incorporam a rede de balanço, o acocorar-se e tramas arejadas adequadas ao clima tropical. Uma produção que Ortega (2008, p. 133) associa a Gio Ponti - defesa da tradição artesanal italiana -, e ao mesmo tempo aponta não para a mera incorporação de formas, mas para a recuperação da funcionalidade e síntese de tal classe de objetos, na geração de uma cultura essencialmente moderna e popular, já em seus primeiros anos em terras brasileiras.

\section{Lina e o moderno brasileiro}

Não se trata, portanto, apenas do evidente entusiasmo frente a um país "jovem", em que a arquitetura (moderna) constitui instrumento livre dos preconceitos sedimentados no Velho Mundo; trata-se também de um moderno criticamente informado, tanto de seus instrumentos e significados, quanto de seus limites e possibilidades, agora, no que concerne à construção de uma nação moderna. Isto é claro em "Lettera dal Brasile" (1956). Lina qualifica as críticas dos arquitetos estrangeiros como construtivas, "mesmo quando ásperas e apressadas"; faz referências ao Ministério da Educação e Saúde Pública (1936) e a BurleMarx e efetua a crítica da arquitetura brasileira do ponto de vista da terra e seu povo, conseguindo ver o sentido de urgência e improvisação de "uma humanidade que quer organizar-se rapidamente, ganhar tempo: uma humanidade que trabalha e merece um momento de meditação e não a anulação esnobe de uma pseudo-cultura" (Instituto Lina Bo e P. M. Bardi, 1993, p. 95). Não ignora, por outro lado, as contradições visíveis no "contraste entre as favelas e as construções modernas" e nas "pedras muito bonitas, perfeitamente lapidadas pela natureza servindo, sob piche, como "fundo" para asfaltar a estrada para lá de Itararé" (Instituto Lina Bo e P. M. Bardi, 1993, p. 40).

Esta postura frente ao moderno brasileiro, forjada na oficina da terra e da vida, revela-se desde no hábil desfiar de nomes populares de pássaros ${ }^{7}$ até no design de joias a partir de gemas brasileiras, na museologia e na formação artística e de público, no periodismo e na crítica de arquitetura ${ }^{8}$.

O permanente envolvimento de Lina Bo Bardi com a questão do museu moderno é apontado por Azevedo (1995, p. 10) como significativo da junção entre o político e o cultural em sua produção. Traça-se precocemente a diferença entre o museu europeu, de caráter seletivo, e o dos "países de cultura em início, desprovidos de um passado", dedicado à instrução e formação. Aproxima-se do conceito norte-americano de museu, ligado à democratização do acesso à arte e à cultura, na instalação do MASP (1947) da rua 7 de Abril. Esta aproximação é sistematizada em textos como "Os museus vivos nos Estados Unidos" (1950) e "A função social dos museus" (1950), em que Lina afirma que "é neste novo sentido social que se constitui o Museu de Arte de São Paulo, que se dirige à massa não informada nem intelectual, nem preparada" (Azevedo, 1995, p. 12), o que resulta na combinação de pinturas, esculturas e outros objetos artísticos, na recusa de sequências cronológicas e na colocação de legendas atrás das obras. O IAC - Instituto de Arte Contemporânea - é resultado desta orientação, oferecendo cursos de desenho industrial, fotografia, pintura, desenho, música e artes aplicadas adaptados às especificidades e necessidades do país 9 . Projeta o Museu de Arte de São Vicente (1952), o inaudito "museu à beira do oceano" e, posteriormente, a sede do MASP (1957) na avenida Paulista, em que sintetiza as reflexões em torno do tema do "museu com função social". Estas prosseguem na estruturação do Museu de Arte Moderna da Bahia, instalado 
no foyer do Teatro Castro Alves em Salvador, e do Museu de Arte Popular, cuja estruturação dialoga com a intervenção efetuada no Solar do Unhão; respectivamente, no museu enquanto condensador e catalisador de iniciativas culturais - próximo à ideia de rede--, e no museu enquanto centro de pesquisa, no caso, do pré-artesanato enquanto fonte para um desenho industrial brasileiro.

Os mesmos princípios estão presentes na criação da revista Habitat em 1950, cujo programa é assim explicitado em seu número inaugural: "escolhemos para título desta revista uma palavra intimamente ligada à arquitetura, à qual damos um valor e uma interpretação não apenas artística, mas uma função artisticamente social" ("PREFÁCIO", 1950, p. 1).

A crítica de arquitetura de Lina é igualmente reveladora da sua relação com a arquitetura brasileira. Debatendo o perfil do arquiteto brasileiro "Casas de Artigas" (1950) o descreve como "espírito retraído", que "trabalha na sombra" e "não aparece nas revistas", cuja arquitetura "não é 'vistosa', nem se impõe por uma aparência de modernidade, que já hoje se pode definir num estilismo"; tampouco apela para "efeitos forçados, da forma livre" mas é resolvida "em cada pormenor", segundo uma "moral que é sempre severa" (Rubino e Grinover, 2009, p. 67-8). Na outra mão, retira a forma livre - fábrica Duchen (1950) - do âmbito da decoração para enquadrá-la, em "Duas construções de Oscar Niemeyer" (1951), num "segundo período racionalista", marcado pela exploração do potencial plástico e estrutural do concreto armado, conforme previsto por Wright e Nervi. O mesmo esforço de reorientação da cultura arquitetônica local é visível em "Bela criança" (1952). Refuta a tese de Zevi de que "a arquitetura brasileira já marca estrada para uma academia", posicionandose explicitamente sobre a relação entre a arquitetura brasileira tradicional e moderna - Lúcio Costa -, ao afirmar que "a arquitetura contemporânea brasileira não provém da arquitetura dos Jesuítas, mas do 'pau a pique' do homem solitário, que trabalhosamente cortara os galhos na floresta" (BARDI, 1952: 3). Não se furta a prescrever o remédio para tal mal: a fidelidade ao homem - dado comum aos três textos - e a poesia íntima da terra brasileira.

Enfim, a trajetória de Lina Bo Bardi é marcada, desde a sua chegada ao Brasil, por um olhar já formado e amadurecido, adotando postura independente e original, que desenvolve em novas temáticas e produções. O "senso profondo di sfida della natura e di aiuto primario all'uomo", antes conferido por Lina à arquitetura moderna brasileira do que atributo próprio desta última, sinaliza para o que é decisivo em seu encontro com o Brasil, revelando indiretamente a concepção que Lina tem do moderno: dirigido ao cotidiano, afinado a um olhar aguçadamente antropológico e que recupera uma relação fecunda com a história; atento às formas da arquitetura rural e espontânea, ao pré-artesanato e às manifestações de arte popular,

questioni alle quali la progettista aveva già iniziato a interessarsi in Italia, assumono sempre maggiore importanza, diventando motivo guida di una ricerca espressiva che ha le sue radici nei i tentativi di recupero di elementi vernacolari nel linguaggio architettonico modemo operati sulle suggestioni delle prime letture di Sibyl Moholy-Nagy o, per restare in Italia, di Giuseppe Pagano. (Miotto e Nicolini, 1998, p. 13-6)

\section{Pesquisas arquitetônicas na nação moderna}

A produção de Lina Bo Bardi entre a sua chegada ao Brasil e sua estada na Bahia, portanto, constitui-se antes como continuidade e evolução de uma pesquisa do que em mera adesão a um projeto moderno local, da mesma forma que sua produção em São Paulo já contêm dados das pesquisas que ela desenvolve na Bahia.

Miotto e Nicolini (1998, p. 18) notam que tanto a casa de vidro (1951) quanto a casa de Canoas (1953) de Oscar Niemeyer são perfuradas por elementos da natureza, mas que, enquanto nesta a relação com a natureza e o sítio se dá no sentido fusão e construção do espaço, a casa do Morumbi apresenta-se como um observatório a partir do qual se estabelece um diálogo qualificado com o ambiente, "uno sguardo scientifico-poetico":

É evidente come la visione che Bo Bardi restituisce del Brasile appartenga a un occhio straniero, a un osservatore che "guarda da fuori", che vede per la prima volta e ha la capacità di conferire nuovi significati agli elementi essenziali, quasi comuni della 
10 É altamente significativo que o prédio localize-se sobre - cruzamento da avenida "Paulista" com a avenida "Nove de Julho", o que ajuda a explicar o caráter simbólico de sua implantação no antigo Trianon, como narrado por Rubino (2002)

11 Termo usado por Lina para designar o SESC Pompéia, e que é usado aqui para assinalar a dimensão urbana do MASP, ciente das particularidades de cada momento e projeto.

Figura 2: Masp, 1957. Fonte: Marcia Minillo/Rede Brasil Atual. cultura brasiliana, instaurando relazioni nuove, altre letture; ma nello stesso tempo questo incontro, o scontro, con l'esotico é fatale strappo politico, che rimette in discussione continuamente la matrice europea del proprio universo di riferimento. (Miotto e Nicolini, 1998, p. 18)

A ideia de casa de vidro potencializa tal diálogo como acontecimento notável, ao mesmo tempo em que implica em indeterminação dos limites entre natureza e espaço edificado. É nítida esta intenção na construção da imagem de Lina junto ao pano de vidro olhando a paisagem. Na casa Valeria Cirell (1958) a abordagem de Lina é diversa: materializando no próprio espaço este diálogo, conecta arquitetura e natureza numa chave híbrida, por meio de volumes opacos, rugosos e introvertidos, teto verde e uma cobertura de palha sucessivamente modificada (Miotto e Nicolini, 1998, p. 55), na direção da ruptura com a ideia de linearidade e finitude temporal em favor de uma obra aberta, em permanente transformação.

Estas pesquisas convergem no MASP da avenida Paulista (1957), seja em sua relação com o sítio agora não mais o subúrbio, mas o ponto nodal de um complexo metropolitano ${ }^{10}$-, seja em relação à ideia de observatório, mirante e fortificação - "cidadela da liberdade"11. Uma "fortificação cidadã" que expande as ideias sobre a função social do museu no sentido da cidadania, materializada em seu hall cívico, sede de reuniões públicas e políticas, no belvedere enquanto local de grandes concentrações coletivas (Figura 2) e na horizontalidade das salas de exposição, que eliminam toda noção de hierarquia, juntamente com os suportes de concreto e vidro projetados pela arquiteta, a iluminação natural e a abertura visual para a cidade, que remete a apreciação das obras de arte ao espaço social que as abriga e na qual são produzidas.

Finalmente, ainda no sentido da convergência dos aportes da arquiteta, figura a expressão de valores cívicos, que remetem à noção de monumentalidade, fundamentando a opção pelas "soluções diretas, cruas", enquanto expressão do fazer coletivamente, e do fazer-se enquanto coletividade.

Ou seja, ao invés de constituir-se em ápice e fechamento de uma primeira fase de produção de Lina Bo Bardi, o MASP condensa tanto as questões quanto a forma com que Lina as vinha enfrentando e enfrentará, nos anos seguintes.

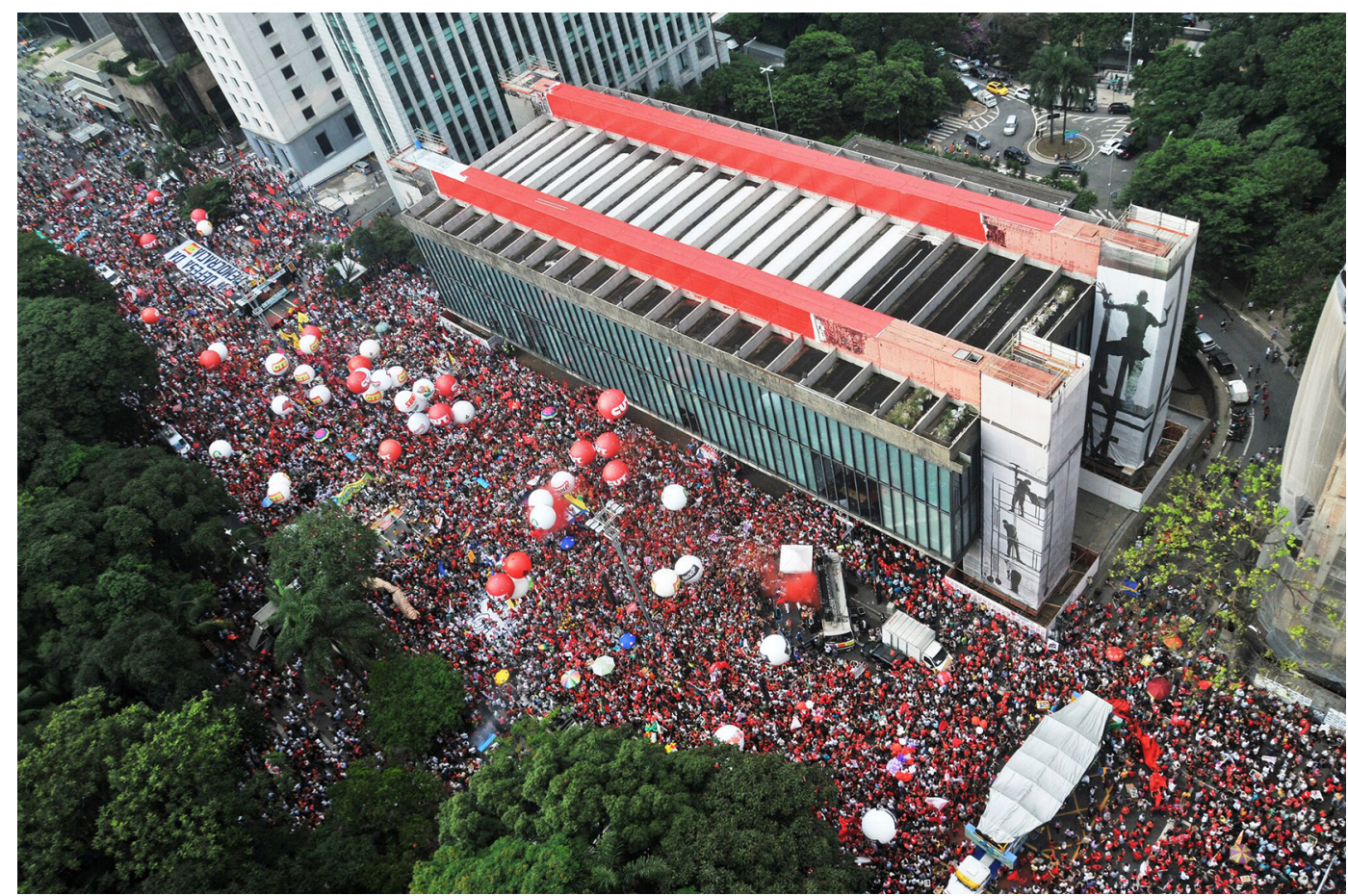




\section{Um projeto para o Brasil}

12 Lina responde, em "In difesa di Brasília" (1964), ao artigo "Brasilia: le forme denunciano i contenutti tremendi" (1964), de Bruno Zevi, crítica que vinha desde "Enchiestra su Brasília. Sei? Sulla nuova capitale americana" (1960). A defesa de Brasília se mantém no I/ Inquérito Nacional de Arquitetura (1982).

13 Lina concebe em 1960 a cenografia para a peça Ópera dos três vinténs, de Brecht, e em 1961 para Calígula, de Camus.

14 Nestes ambientes, trava contato com personagens como Diógenes Rebouças, Edgar Santos, Agostinho da Silva, Martin Gonçalves, Hans Joachim Koelreutter, Yanka Rudska e Pierre Verger; em Recife, com Germano CoeIho, Ariano Suassuna, Hermilo Barbosa, Abelardo da Hora, Paulo Freire e Francisco Brennand; em Fortaleza, com Lívio Xavier, organizador do Museu de Arte da Universidade do Ceará.

15 Anelli (2014) fornece um panorama da produção de Lina Bo Bardi que enfatiza a moldura política e, sobretudo, detalha as relações estabelecidas entre instituições e agentes sociais, dando conta, em especial, da progressiva deterioração do apoio das instâncias governamental, universitária e da mídia - Diário de Notícias, do conglomerado de Chateaubriand - a Lina.

16 Anelli (sd., p. 35) detalha a transferência do MAMB ao Solar do Unhão em 1963, o planejamento do Centro de Estudos e Trabalho Artesanal e a Escola de Desenho Industrial. Miotto e Nicolini (1998, p. 20), Polígono della Siccità. M. Bardi, 1993, p. 153).
Lina não participa do concurso de Brasília. Ao defendê-la perante a crítica internacional ${ }^{12}$, nos moldes dos textos de 1952 e 1956, demonstra mais uma vez sua grande capacidade de convivência política, ao contrapor ao julgamento formal a solidariedade política e moral, e avalizar um projeto que é a muito bastante diferente do seu. Durante a construção, inauguração e primeiros anos de vida da nova capital, atua em Salvador. Como afirmam

...mentre la nuova generazione di architetti carioca si avvia a inaugurare la stagione della modernizzazione indicata da Le Corbusier - che avrà il suo ápice nell'utopica impresa di Brasília - Bo Bardi è impegnata nella zona più depressa del Brasile, nel Nord-est, nel

A partir de 1958, Lina leciona teoria da arquitetura na Universidade da Bahia; compartilha o ambiente de vanguarda baiana em que nasce o Cinema Novo e se dá a introdução das peças de Brecht e Camus no Brasil - manifestações que Lina abriga no MAMB (1959 - 1964)13 -; estabelece relações com artistas e intelectuais envolvidos na criação do MCP - Movimento de Cultura Popular - em Recife ${ }^{14}$. Um movimento cultural qualificado posteriormente por ela como "um discurso sócio-político, ligado diretamente à economia e à história do Brasil", "um fermento, uma violência, uma coisa cultural no sentido histórico verdadeiro de um País, que era o conhecer de sua própria personalidade" (Instituto Lina Bo e P.

Um dos personagens fundamentais desta história é o economista paraibano Celso Furtado, pensador maior do desenvolvimento brasileiro em obras como Formação Econômica do Brasil (1959) e Desenvolvimento e subdesenvolvimento (1961), e criador da SUDENE (1959). Furtado integra a CEPAL - Comissão Econômica para a América Latina e o Caribe - pouco depois de sua criação, em 1948. Lá, participa da formulação da Teoria do Subdesenvolvimento, que parte do modelo centro-periferia para superar as interpretações vigentes da economia latino-americana, em favor do subdesenvolvimento como formação econômica e social peculiar, e não fase correspondente à "infância" dos países capitalistas centrais. Teoria que marca o projeto moderno brasileiro ao pregar a necessidade de se direcionar a sua economia "para dentro", através de uma ação orquestrada pelo Estado, cuja intervenção na promoção da industrialização, infraestrutura, reforma agrária-aspecto menos lembrado - e na articulação dos agentes sociais é tida como indispensável à superação do subdesenvolvimento, e consequentemente, à modernização. Anelli (2014) descreve como, em sua atuação na Bahia, Lina "became engaged more and more in Celso Furtado's Developmentalism project for Brazil's northeast" 15 , para o que contribui a convergência da arquiteta com as políticas de suporte ao artesanato formuladas por Rômulo de Almeida, que consideravam o artesanato como o primeiro passo em direção ao trabalho na fábrica, sugerindo seu desenvolvimento por meio de instituições de especialistas (Anelli, 2014).

Os argumentos e propostas da passagem para a década de 1960 em favor dessa iniciativa de-senvolvimentista são os mesmos utilizados por Furtado em sua crítica ao modelo vigente, em fins desta década. Tal coincidência sugere o apro-fundamento da evolução da teoria cepalina ao longo destes anos. Sem deixar de incluir uma análise de classes sociais, Furtado afirma que no Brasil "pós-50 anos em 5" a industrialização efetuada segundo padrões tecnológicos dos países desenvolvidos - poupadoras de mão-de-obra e de alta densidade de capital - impossibilitava a formação do mercado interno, resultando em má alocação de recursos, capacidade ociosa, alta de preços, concentração de renda, estagnação. A resposta, em Um projeto para o Brasil (1968), passaria pela utilização de técnicas que "empreguem mais trabalhadores, paguem mais salários e ampliem o mercado consumidor" (Mantega, 1985, p. 86-7)

Em que pese o fato da fórmula ser ainda a cepalina, de intervenção do Estado na economia em prol dos interesses da população, são estas preocupações compartilhadas por Lina Bo Bardi. Segundo Miotto e Nicolini (1998:20), "agli occhi di Bo Bardi, l'accelerata industrializzazione del Paese estremizza la contraddizione del grande "equivovo occidentale" com tratti quasi violenti".

É este o contexto em que se dá a criação do Museu de Arte Popular (1959), por Lina Bo Bardi e da Artene (1961), por Celso Furtado.

O MAP, originalmente Centro de Documentação da Arte Popular e Centro de Estudos Técnicos ${ }^{16}$ 
Figura 3: Fac-símile de página da revista Mirante das Artes, n. 6, 1967, com Celso Furtado, Darcy Ribeiro e Anísio Teixeira. Fonte: Instituto Lina Bo e P. M. Bardi, 1993. com atividades didáticas, laboratórios experimentais e pesquisas sobre o pré-artesanato nordestino estrutura-se em torno de dois objetivos: técnico - estabelecimento de princípios norteadores do desenho industrial brasileiro - e social - "reintegrar ao estágio de desenvolvimento social e técnico da humanidade, uma parcela da população marginalizada pelo processo excludente da industrialização bra-sileira". Um ano após a restauração do Solar, Lina Bo Bardi monta com Martin Gonçalves a Exposição Bahia (1959), realizada na V Bienal de São Paulo. Ainda sob o otimismo nacional-desenvolvimentista de JK, trata-se já de questionar o lugar ocupado pela chamada arte popular, de reivindicar os valores humanos nela fixados, de alcançar a plenitude de expressão de tais valores e de promover sua reabsorção pelo momento histórico vivido.

Estabelece-se neste momento a estrutura discursiva que permeia a atividade posterior da arquiteta: a negação da abordagem da cultura popular enquanto folclore; a vinculação do pré-artesanato às condições materiais do meio e à experiência de quem o fabrica - segundo Azevedo (1995, p. 58), revelando a visão gramsciana, de fazer valer o que há de positivo na experiência de vida das classes oprimidas -; o reconhecimento da capacidade de iniciativa e autonomia da população; a noção de cidadania embutido no reconhecimento desta produção préartesanal enquanto manifestação artística - "acusação dum mundo que não quer renunciar à condição humana apesar do esquecimento e da indiferença" (Instituto Lina Bo e P. M. Bardi, 1993, p. 158).

Da mesma forma, aparece com clareza o aporte crítico-civilizacional, de corte antropológico, que vê nos "objetos comuns, carinhosamente cuidados", "exemplo importante para o moderno desenho industrial", já devidamente despojado de conteúdos repressivos ocidentais (Instituto Lina Bo e P. M. Bardi, 1993, p. 134).
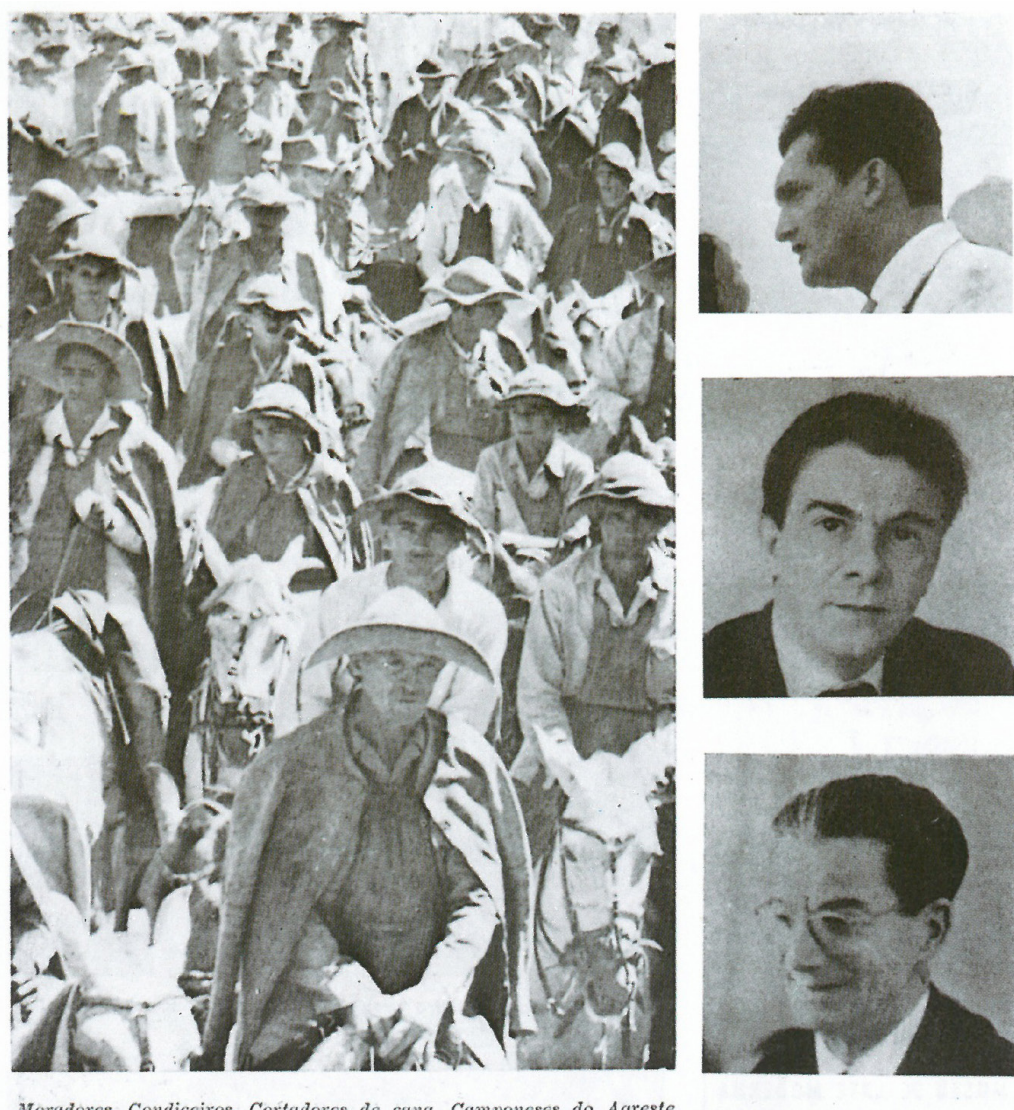

Colso Furtento: pelu térnicen conttru o bucharelismo.

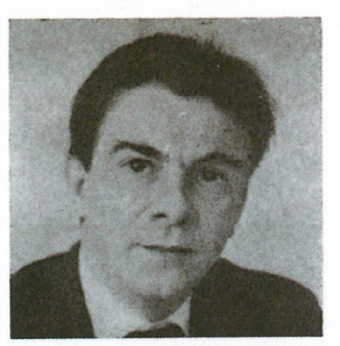

- balazeco critico da situaçèo cultural do prais antecedente aos pulavra cultural também em sen. so politico), tem que ser feito com extremo rigos, eliminando a negativa a respetio do formusitivo" acusade de 'politica impura'. Fste brilanco, pelas terriveis conseque ncias de abril de 64 é imadiavel. A antecedente politicu do 'pollice verso' tem que ser $\mathrm{ri}$ evitar futuros erros imperdociveis, para reengajar milhares de jovens de ianguarda perdidos nas aйvidas e no pessimismo.

Darcy Ribeiro: pela Nova Unicersiadue contra o Latifundio

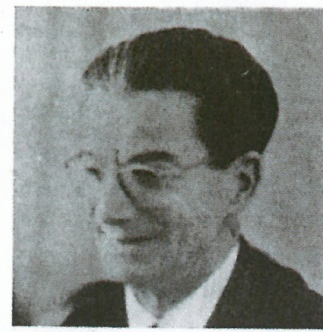

Anisio Teixeira: pela Escole Pablica, Universal e Gratuita

Moradores, Condiceiros, Cortadores de cana, Camponeses do Agreste ou Trabalhadores da Ci
dena it näo-cidadania. 


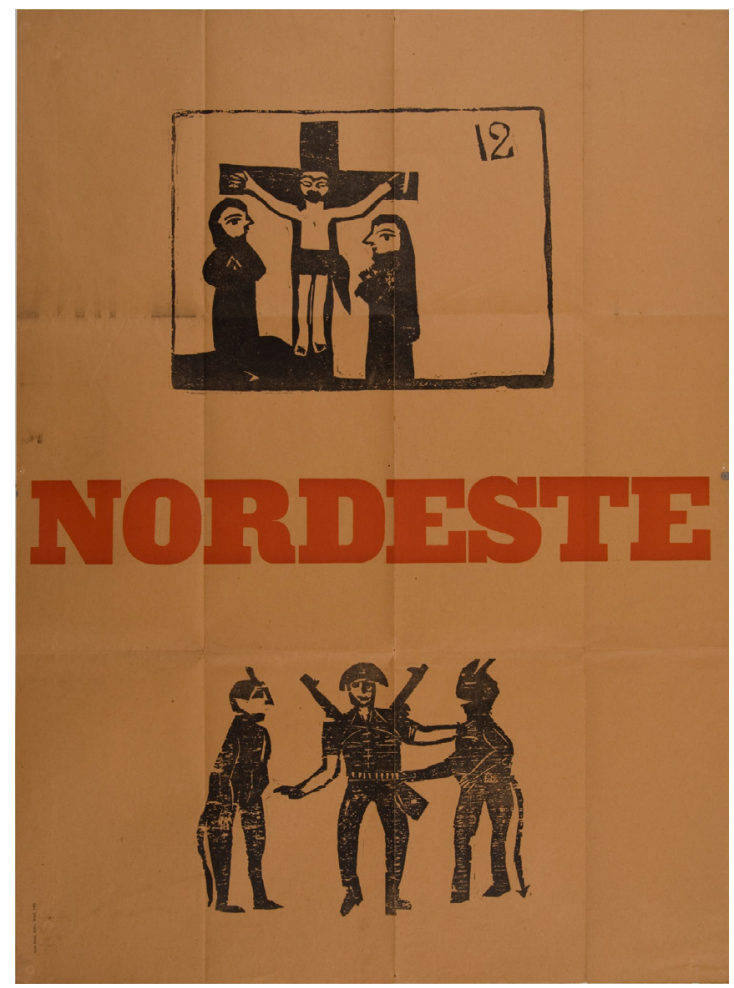

Figura 4: Cartaz da Exposição Nordeste, 1963. Fonte: Instituto Lina Bo e P. M. Bardi, 1952
A pesquisa empreendida no MAP tem paralelos com a atividade da ARTENE, que é assim descrita por Lina:

Não era uma iniciativa romântica do Nordeste, era um frio plano de financiamento sem preocupações estéticas. Um plano intermediário que desapareceria com o desenvo/vimento e a elevação das rendas. $\mathrm{Na}$ "base" estava o levantamento das condições sócioeconômicas do Povo Nordestino rural e semi-rural dedicado ao "artesanato": rendeiras, ceramistas, funileiros, marceneiros, tecelóes, etc. Desaparecido o corpo de sociólogos, antropólogos e economistas que se dedicavam àquela ação e pesquisa, a ARTENE subsistiu no Recife como lojinha de lembranças para turistas. (Bardi, 1994, p. 62)

A ARTENE é criada no conturbado ano da posse e renúncia de Jânio Quadros e da posse de João Goulart sob regime parlamentarista, cerca de um ano antes da nomeação de Furtado para o Ministério do Planejamento, onde elabora o Plano Trienal. Este plano troca a abordagem setorial do Plano de Metas por uma leitura mais globalizante da economia brasileira da época, além de contemplar setores não industriais (educação, agricultura, reforma agrária) e a questão da inflação. Assim, a ARTENE é contemporânea das grandes mobilizações sociais pelas Reformas de Base, que Lina Bo Bardi antecipa em 1961:

O Brasil está conduzindo hoje, a batalha da cultura. Nos próximos dez, talvez cinco anos, o país terá traçado os seus esquemas culturais, estará fixado numa linha definitiva: ser um país de cultura autônoma, construída sobre raízes próprias, ou ser um país inautêntico, com uma pseudo-cultura de esquemas importados e ineficientes. (...) O Brasil, hoje, está dividido em dois: o dos que querem estar a par, dos que olham constantemente para fora, procurando captar as últimas novidades para jogá-las, revestidas de uma apressada camada nacional, no mercado da cultura, e o dos que olham dentro de si em volta procurando fatigadamente nas poucas heranças de uma terra nova e apaixonadamente amada, as raízes de uma cultura ainda informe, para construí-la com uma seriedade que não admite sorrisos. (Instituto Lina Bo e P. M. Bardi, 1993, p. 141)

A Exposição Nordeste (1963) (figura 4) marca o encerramento de suas atividades na Bahia. Consoante ao momento político então vivido, a arquiteta leva ao limite o "sentido de moderna 
realidade" presente na simplificação extrema, na realidade dos materiais, no potencial expressivo da miséria - não indigência -, conforme apontavam as pesquisas formais do Cinema Novo, na direção de um humanismo técnico que mira radicalmente a experiência de vida da população e seus saberes:

Matéria prima: o lixo.

Lâmpadas queimadas, recortes de tecidos, latas de lubrificantes, caixas velhas e jornais. Cada objeto risca o limite do "nada" da miséria. Esse limite e a contínua e martelada presença do "útil" e "necessário" é que constituem o valor desta produção, sua poética das coisas humanas nãogratuitas, não criadas pela mera fantasia. É neste sentido de moderna realidade que apresentamos criticamente esta exposição. Como exemplo de simplificação direta de formas cheias de eletricidade vital. Formas de desenho artesanal e industrial. (Instituto Lina Bo e P. M. Bardi, 1993, p. 158)

\section{De novo, a resistência}

O golpe civil-militar reprime maciçamente o movimento cultural instaurado na Bahia, Lina Bo Bardi é processada, os tanques da base de Amaralina são posicionados em frente do Museu de Arte Moderna da Bahia, e ela é obrigada a deixar a Bahia.
A Exposição Bahia (1959) é reembalada e enviada de volta de Roma sem chegar a ser exposta em 1965, ocasião em que Bruno Zevi publica no jornal L'Espresso o artigo "L'arte dei poveri fa paura ai generali" (1965). A republicação do texto de apresentação da Exposição Nordeste após o golpe militar, sob o título "Manifesto da Exposição Nordeste" (1967), na revista Mirante das Artes, é reveladora dos dilemas e desafios impostos aos projetos modernizadores amadurecidos no período democrático, pela dizimação do modelo político, econômico, social e cultural ao qual eram aderentes, e pela imposição do modelo conservador e autoritário, seu oposto. Afinal, quais significados a obra de Lina Bo Bardi adquire, antes e depois do golpe militar?

O sentido de monumentalização e incorporação técnica contido na pesquisa do pré-artesanato brasileiro fundamenta-se na ideia de construção da cidadania, que implicava num projeto civilizatório. Os "generais" não combatiam tanto a "arte dos pobres", quanto a ideia de conquista da cidadania pela população. Um projeto de Brasil moderno que convergia ao de Celso Furtado, e que é vencido, juntamente com quaisquer outros projetos vigentes ou possíveis, em 1964.

A reiteração, sem modificações, desse projeto modernizador - como demonstra a reprodução
Teatro Castro Alves, 1964

Fonte: Instituto Lina Bo e P. M. Bardi, 1993.

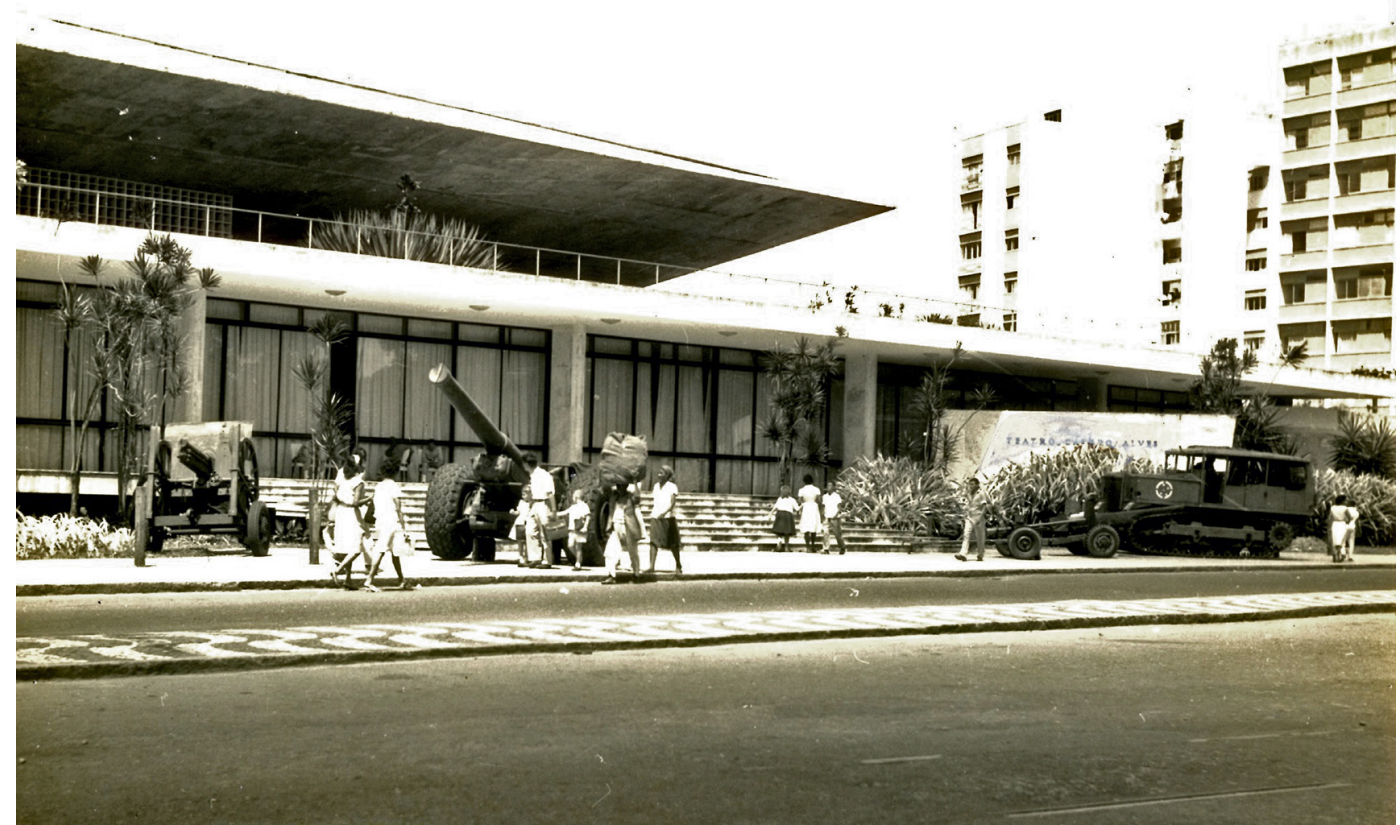


17 Nesse sentido,o design da Cadeira de Beira de Estrada (1967) remete à abordagem de Artigas na contemporânea casa Elza Berquó (1967).

Figura 6: Cadeira de beira de estrada. Fonte: Instituto Lina Bo e P. M. Bardi, 1952. do texto de 1963 em 1967 - em situação oposta àquela em que se deu sua geração, e portanto, sabidamente contrária à sua concretização, de um lado mostra a perplexidade que marca a sociedade brasileira no período imediatamente anterior e posterior ao golpe. No caso de Lina, uma perplexidade lúcida que a faz reafirmar, antes do acirramento da ditadura, em "Cinco anos entre os brancos" (1967), sua proposta de inter-relação entre pré-artesanato e indústria, "no quadro do desenvolvimento do país" (Instituto Lina Bo e P. M. Bardi, 1993, p. 162), ao mesmo tempo em que lembra a "atmosfera recente, porém terrivelmente distante" da produção cultural baiana anterior e a "destruição do habitat cultural".

De outro lado, a reiteração de tal projeto modernizador em quadro a ele contrário, faz inverter o seu significado consubstanciando-o enquanto iniciativa de resistência cultural, ao marcar o abismo entre sociedade e modelo imposto e denunciar a irracionalidade do processo social brasileiro ${ }^{17}$. Esta condição, comum e mesmo inevitável à arquitetura moderna brasileira em fins da década de 1960, marca as posições tomadas por alguns de seus principais agentes, num debate como aquele sobre o significado do desenho- prática profissional - sob a ditadura. Se Artigas defende, na famosa aula inaugural de 1967, a manutenção do projeto enquanto exercício do campo de conhecimento do arquiteto, Lina adota atitude diversa, mais complexa e crítica, insistindo em que "antes de enfrentar o problema do industrial design em si mesmo, você tem que enquadrá-lo dentro de um contexto sócio-econômico-político, na estrutura do lugar, do país, nesse caso o Brasil" (Instituto Lina Bo e P. M. Bardi, 1993, p. 186)

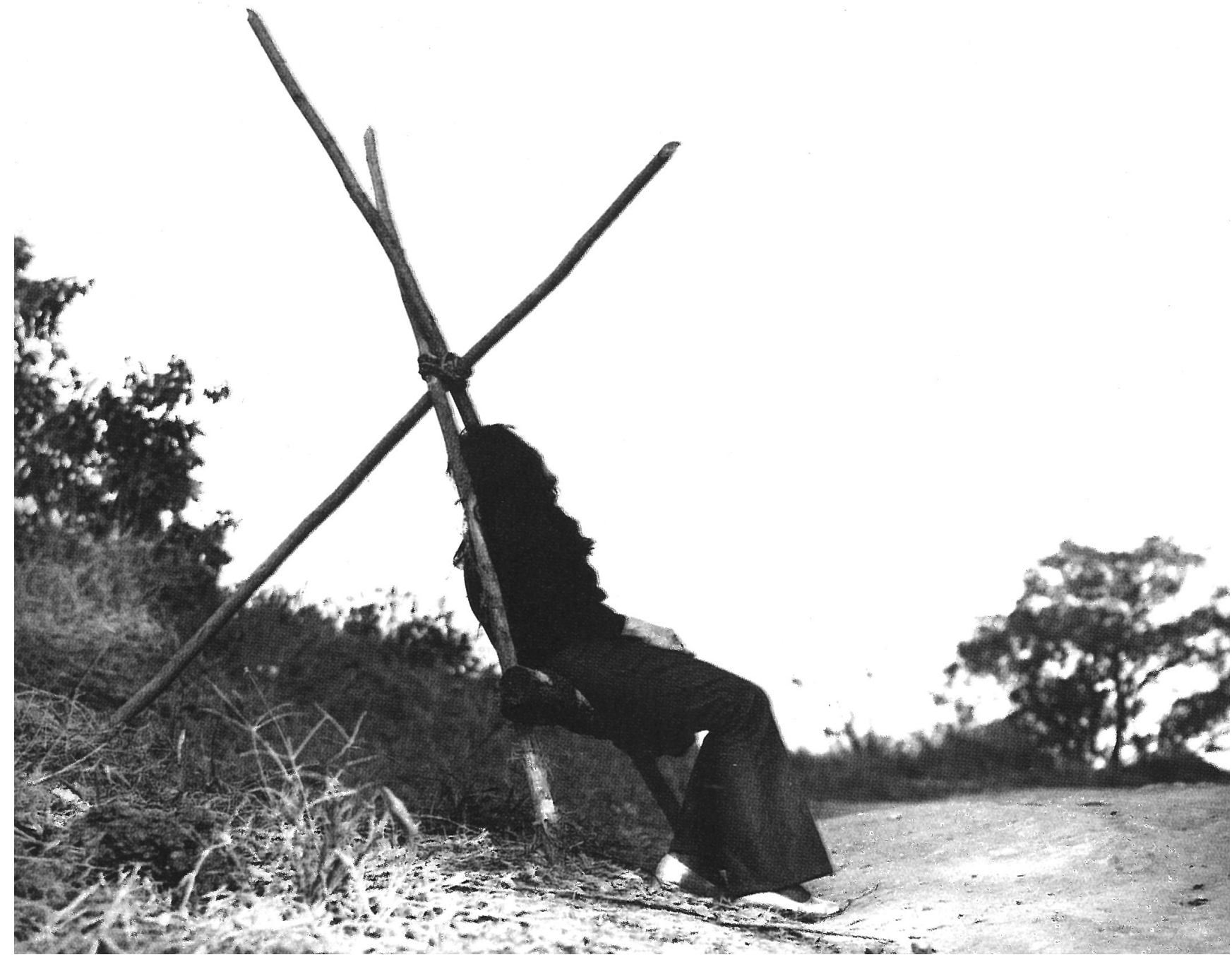


18 Como faz Florestan Fernandes (1974), que vê no golpe civil-militar uma "revolução autocrático-burguesa."
Esta atitude crítica e o design dela decorrente, na verdade, antecipam a fase mais brutal da ditadura inaugurada com o Al-5. É este o sentido de sua atuação nos anos seguintes, concebendo cenários, entre outros, para Na Selva das cidades (1967) e Gracias Señior (1971), peças dirigidas por José Celso Martinez; e montando as exposições $A$ mão do povo brasileiro (1969) e Repassos (1975), com Edmar de Almeida, em que a miséria social toma efetivamente ares de loucura:

Esta não é uma exposição de arte religiosa.

Nos períodos difíceis da história de um país quando as estruturas se desfazem o misticismo é o último recurso que tira o homem da passividade. Assim - a miséria até a loucura de Mariazinha-tecedeira, de Waldir e Arlindo-consertador de carro de boi, habitantes de Martinésia, Triângulo Mineiro. (Instituto Lina Bo e P. M. Bardi, 1993, p. 200)

Dois anos depois, em "Tempos de grossura" (1977), este panorama desolador é explicado em termos de análise econômica e social e do design, em especial a consciência da inviabilidade do retorno a "corpos sociais" extintos como antídoto para tal processo sem nunca desprezar o reexame do passado recente do país e de sua cultura:

Qual a situação de um país de estrutura capitalista dependente, onde a revolução nacional democráticoburguesa não conseguiu se processar, que entra na industrialização com restos de estruturas oligárquiconacionais?

O Brasil entra em último na história da industrialização de marco ocidental, portador de elementos da pré-história e da África, rico de seiva popular. Todas as contradições do grande equívoco ocidental se apresentam contemporaneamente ou em tempo curto no seu processo de modernização, com os traços violentos de uma situação falimentar.

O levantamento cultural do pré-artesanato brasileiro podia ter sido feito antes do país enveredar pelo caminho do capitalismo dependente, quando uma revolução democrático-burguesa era ainda possivel. (...) O Brasil tinha chegado num bívio. Escolheu a finesse. (Instituto Lina Bo e P. M. Bardi, 1993, p. 210)
Revela-se aqui novamente a lucidez da arquiteta. Lina é uma das únicas que assumem a obsolescência do projeto moderno brasileiro após a rápida consolidação do modelo econômico do regime militar ${ }^{18}$. Ao contrário do que preconizada Furtado em fins da década de 1960, o arrocho ainda maior dos salários a partir de 1964 não apenas não gerou estagnação, como levou ao "milagre econômico", "erro esse, aliás, compartilhado não apenas pelos partidários do Modelo de Substituição de Importações, como também por praticamente todos os pensadores da esquerda brasileira da época, com raras exceções" (Mantega, 1985, p. 101).

Lina enfrenta exemplarmente esta questão. Transformando seu projeto explicitamente em instrumento de resistência cultural, não rejeita a indústria em si, tampouco perde a esperança na experiência moderna, aposta na falência do desenho ou defende o que fica à margem do sistema. Ao tratar das conclusões do XII Congresso Mundial de Arquitetos (1975) em "Planejamento ambiental: 'desenho' no impasse" (1976), Lina contrapõe a "procura antropológica" à "procura estética" da arte ocidental, na tarefa de desmistificação do "design como arma", em termos não de "uma recusa em bloco, mas um cuidadoso processo de revisão", afirmando que "o problema é fundamentalmente político-econômico" (Instituto Lina Bo e P. M. Bardi, 1993, p. 216). Vê que a captura do design pelo capital leva consigo as conquistas básicas do movimento moderno. Defende, no lugar do não-planejamento suicida da reação anti-tecnocrática, o enfrentamento do quadro a partir da liberdade enquanto "capacidade de dizer não", a responsabilidade social do artista, e o conceito de planejamento ambiental-baseado na reintegração dos fatores componentes da cultura.

Finalmente, aparecem aqui os pontos de contato e divergência entre Lina Bo Bardi e os arquitetos Sérgio Ferro, Flávio Império e Rodrigo Lefèvre; Lina defendendo a revisão em detrimento da recusa em bloco da experiência moderna e da volta à visão de John Ruskin e Willian Morris, Ferro partindo desta para originar sua crítica ao canteiro; Lina buscando uma "arquitetura pobre, "não do ponto de vista ético" (Instituto Lina Bo e P. M. Bardi, 1993, p. 100); Ferro, Império e Lefèvre formulando uma "poética da economia" que considera eticamente os esforços envolvidos na construção ${ }^{19}$.
19 Deve-se lembrar ainda rio atuam junto ao Teatro Oficina. 


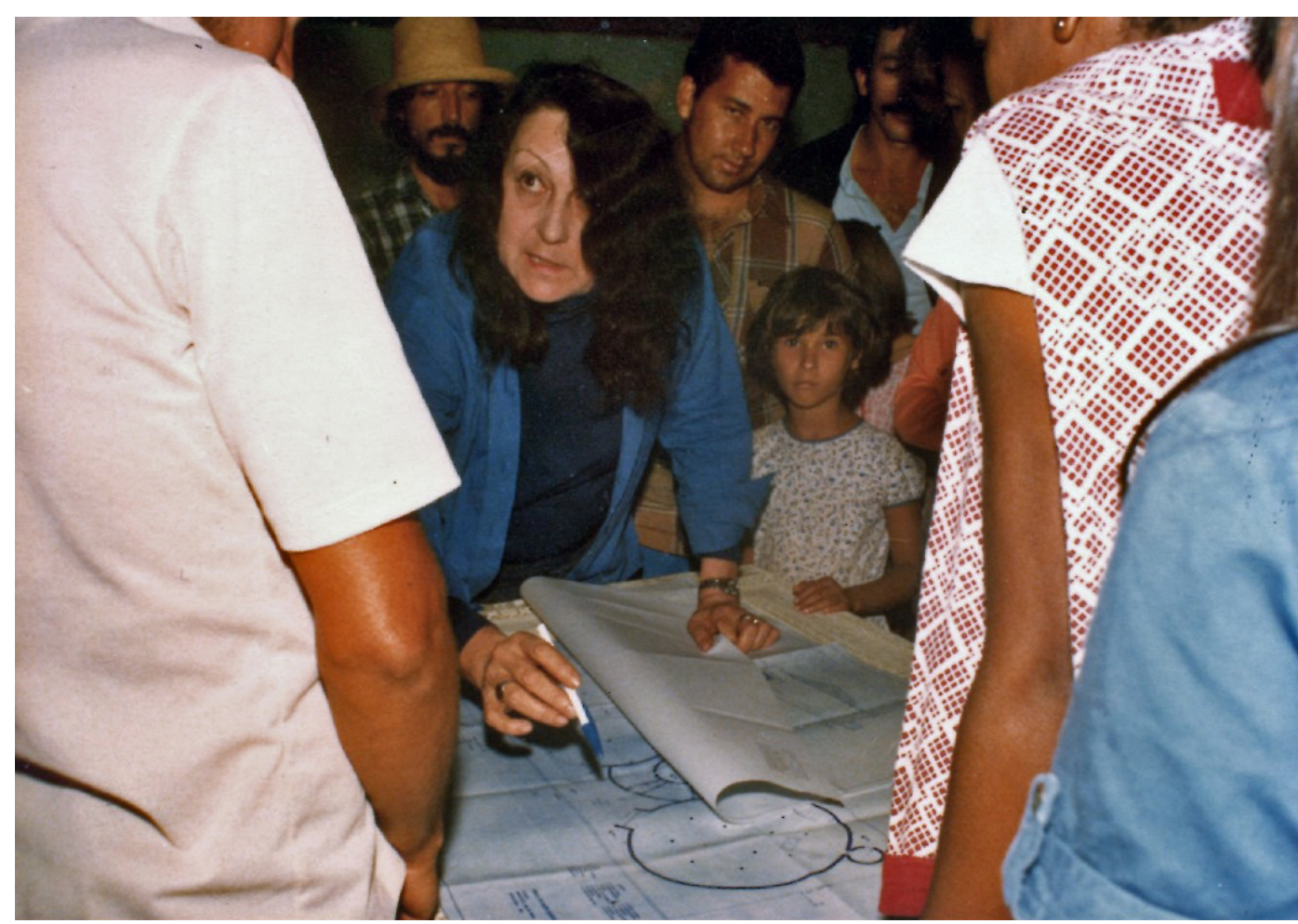

Figura 7: Lina Bo Bardi em apresentação de projeto à comunidade do Espírito Santo do Cerrado, Uberlândia, 1980. Fonte: Instituto Lina Bo e P. M. Bardi, 1993.

20 De que é exemplo importante o Pavilhão para a Expo'70, de Paulo Mendes da Rocha e equipe.
A perene disposição de Lina ao debate intensifica-se nesses difíceis tempos, sua grande capacidade de interlocução fazendo-se presente mais uma vez no debate com um leque de agentes que vão de Artigas ao trio de arquitetos e além, na construção de uma posição de convergência em torno da experiência moderna brasileira. Visível em uma série de textos e projetos da passagem para a década de $1970^{20}$, tal convergência encontra em "Na América do Sul, após Le Corbusier, o que está acontecendo" (1967) um de pontos iniciais, exatamente no argumento de que a implementação da produção em massa na construção de uma sociedade mais justa demanda valores humanísticos presentes justamente na obra do arquiteto franco-suiço, ou "herança racionalista" (Instituto Lina Bo e P. M. Bardi, 1993, p. 184). Lina Bo Bardi entra nos anos marcados pelo Al-5, pela escalada da repressão e a instauração do terrorismo de Estado pela ditadura civil-militar, lutando pela sobrevivência de um projeto de Brasil moderno que, como postula Flávio Motta "não foi perdido, mas tirado".

\section{Conclusão}

Ao longo de sua trajetória por diferentes países, regiões, cidades, conjunturas e temporalidades - da
Europa industrializada, porém destruída pela guerra, ao deprimido polígono das secas, sua "seiva popular" e "eletricidade vital" - Lina Bo Bardi constitui e desenvolve um projeto moderno marcado pela consistência e longevidade de valores e referências intelectuais e arquitetônicas, portador de grande unidade e coerência.

Trazendo em sua bagagem uma formação peculiar e uma experiência singular na Itália, estabelece assim em sua chegada ao Brasil uma relação com a arquitetura moderna local que não se concretiza em termos de vinculação ou enquadramento, tampouco enquanto simples contracorrente ao projeto que orbita em torno de Lúcio Costa. Ao invés disso, tece relações de continuidade na passagem de um lugar em que "a casa do homem ruiu" a outro, em que o construir-se enquanto nação, moderna e ao mesmo tempo popular, deve ter em vista que "uma cadeira de grumixaba e taboa é mais moral que um divã de babados"; um projeto modernizador que é objeto de pesquisa constante, com seus resultados e as novas questões por eles instigadas, em São Paulo, na Bahia, de volta a São Paulo e além.

O conteúdo e o sentido político que perpassam sua obra materializam-se não apenas nas entrelinhas, 
mas numa atuação lúcida e ciente de suas possibilidades e limites, em cada momento - desde os cuidados necessários para que uma "bela criança" cresça forte e sadia, passando pelo bívio em que se escolhe a finesse até o reconhecimento da inviabilidade de estratégias até então vigentes, diante das mudanças estruturais daí decorrentes. Atuação sistematizada em uma série de iniciativas coordenadas que busca horizontes os mais amplos, no intento de intervir na construção da cultura arquitetônica, artística e cultural local; que engloba a criação de um periódico cujo título confere à arquitetura "uma função artisticamente social", a concepção de museus "com função social", a formação de público e produtores, a crítica de arquitetura.

Lina coloca no centro de seu projeto moderno a terra e o homem brasileiro: aquele "que trabalhosamente cortara os galhos na floresta para fazer o pau-a-pique", e que "merece um momento de meditação" que se constrói coletivamente ao construir-se enquanto coletividade, que reivindica a cidadania por meio da arte popular, de seu pré-artesanato e do desenho industrial dele nascente; o homem cuja sanidade é ameaçada pelo esfacelamento das estruturas sociais, e que finalmente exerce a liberdade enquanto capacidade de dizer não. Revela grande capacidade de convivência política ao defender as realizações deste homem, sem deixar de apontar suas contradições; e ao debater com intelectuais e arquitetos como Celso Furtado, Lúcio Costa e Vilanova Artigas.

Seu caráter aberto e generoso lhe permite construir-se como intelectual, construindo a cultura brasileira, ajudando-a e a seus companheiros de luta diante das críticas e eventos mais dolorosos. Sua trajetória adquire, assim, inevitáveis contornos políticos, explicitados com rigorosa franqueza e honestidade intelectual no debate entre os projetos de Brasil moderno.

\section{Referências bibliográficas}

ANELLI, Renato Luiz Sobral. Revendo Lina. In: Lina Bo Bardi arquiteto. São Paulo: MASP, sd.

ANELLI, Renato Luiz Sobral. Lina Bo Bardi and her relationship to Brazil's Economic and Social Development Policy. In: Lina Bo Bardi 100: Brazil's Alternative Path to Modernism. 1ed. Berlim: Hatje Cantz, 2014, v. 1 p. 155-169.

ANELLI, Renato Luiz Sobral. Ponderações sobre os relatos da trajetória de Lina Bo Bardi na Itália. Pós. São Paulo, v. 17, n. 27, p. 86-101, Jun. 2010.
AZEVEDO, Mirandulina Maria Moreira A experiência de Lina Bo Bardi no Brasil: 1947 - 1992. 1995. Dissertação (Mestrado em Estruturas ambientais urbanas) - FAU USP, São Paulo, 1995.

BARDI, Lina Bo. Bela criança. Habitat. São Paulo, n. 2, p. 3, jan/mar. 1951

BARDI, Lina Bo. Tempos de grossura: o design no impasse. São Paulo: Instituto Lina Bo e P. M Bardi, 1994

BARDI, Lina Bo. Uma aula de arquitetura. Projeto. São Paulo, n.133, p.103-108, jul. 1990.

BRUAND, Yves. Arquitetura Contemporânea no Brasil. 4. ed. São Paulo: Perspectiva, 2002

CARRANZA, Edite Galote. Casa Valéria Cirell e o nacional-popular. Pós. São Paulo, v. 21, n. 35, p. 118-138 jun. 2014.

FERNANDES, Florestan. A revolução burquesa no Brasil: ensaio de interpretação sociológica. Rio de Janeiro: Zahar, 1974

INSTITUTO LINA BO E P. M. BARDI. Lina Bo Bardi. São Paulo: Empresa das Artes/ Instituto Lina Bo e P. M. Bardi, 1993.

LIMA, Zeuler Rocha Mello de Almeida. Lina Bo Bardi. New Haven/ London: Yale, 2003.

MANTEGA, Guido. A economia política brasileira. 3. ed São Paulo/ Petrópolis: Polis/ Vozes, 1985.

MIOTTO, Laura, NICOLINI, Savina. Lina Bo Bardi: aprirs all'accadimento. 1. ed. Torino: Texto \& Immagine, 1998

MOTTA, Flávio. Paulo Mendes da Rocha. Acrópole. São Paulo, n.343, p. 17-8, set. 1967.

OLIVEIRA, Olivia de. Lina Bo Bardi: sutis substâncias da arquitetura. São Paulo/ Barcelona: Romano Guerra/ Gustavo Gili, 2006.

ORTEGA, Cristina Garcia. Lina Bo Bardi: móveis e interiores (1947-1968) - interlocuções entre moderno e local. 2008. Tese (Doutorado em Design e Arquitetura) - FAUUSP, São Paulo, 2008. Disponível em: <http://www.teses.usp.br/teses/disponiveis/16/16134/tde-20092010-092353/>. Acesso em: 2015-11-29.

PREFÁCIO. Habitat. São Paulo, n. 1, p. 1, out./dez. 1950.

RESIDÊNCIA no Morumbi. Habitat. São Paulo, n.10, p. 31-40, 1953

RUBINO, Silvana, GRINOVER, Marina (Org.). Lina por escrito: textos escolhidos de Lina Bo Bardi. São Paulo: Cosac Naify, 2009.

RUBINO Silvana. A escrita de uma arquiteta. In: RUBINO Silvana, GRINOVER, Marina (Org.). Lina por escrito. textos escolhidos de Lina Bo Bardi. São Paulo: Cosac Naify, 2009, p. 19-39

RUBINO, Silvana. Rotas da modernidade: trajetória, campo e história na atuação de Lina Bo Bardi, 1947 - 1968. 2002. Tese (Doutorado em Ciências Sociais) - IFCH UNICAMP, Campinas, 2002 